\title{
Diversidade lexical do português de comunidades indígenas do Médio Xingu
}

\section{Lexical diversity in Portuguese of indigenous communities of the Xingu river}

\author{
Fábio Luidy de Oliveira ALVES*
}

Universidade Federal do Pará(UFPA)

\begin{abstract}
RESUMO: O presente estudo apresenta resultados do mapeamento da diversidade lexical do português brasileiro falado em comunidades Asuriní do Xingu e em comunidades Araweté, etnias indígenas que habitam no município de Altamira no estado do Pará. Os resultados limitam-se aos itens lexicais "banguela" e "cigarro de palha" do questionário semântico-lexical que integra o projeto Atlas Linguístico do Brasil. O estudo segue a orientação da Dialetologia pluridimensional e adota procedimentos de projetos de pesquisa que visam mapear línguas faladas por populações indígenas: o Atlas Linguístico do Português em Áreas Indígenas (ALIPAI) e o Atlas Linguístico Sonoro das Línguas Indígenas do Brasil (ALSLIB).
\end{abstract}

PALAVRAS-CHAVE: Dialetologia pluridimensional. Contato linguístico. Variação lexical.

\begin{abstract}
This text aims to present results of mapping of the lexical diversity in Brazilian Portuguese of Asurini Xingu communities and Araweté communities, these ethnic groups live in the municipality of Altamira, in the state of Pará, Northern Brazil. The results refer to the items "toothless" and "straw cigarette" from the lexical semantic questionnaire of the Linguistic Atlas of Brazil project. The study follows orientations of the Pluridimensional Dialectology and procedures adopted by projects that aim to map indigenous languages: Atlas of Portuguese of indigenous Areas (ALIPAI) and Digital Atlas of Brazil's indigenous languages (ALSLIB).
\end{abstract}

KEYWORDS: Pluridimensional dialectology. Languages in contact. Lexical variation.

\footnotetext{
* Doutorando do Programa de Pós-graduação em Letras da Universidade Federal do Pará. E-mail: fabioluidy@hotmail.com 


\section{Introdução}

Os estudos geolinguísticos do português brasileiro (PB) falado em áreas indígenas da Amazônia que se iniciaram nos últimos anos no Brasil destacam uma variedade de português com intensas influências linguísticas, principalmente das línguas indígenas presentes nessas áreas. Trabalhos pioneiros são a tese de Guedes (2017), que registrou variações fonéticas no português falado por etnias Tupi Guarani nos estados do Pará e do Maranhão, e a tese de Costa (2018), que mapeou a variação lexical do PB dos mesmos grupos indígenas que Guedes e destacou o contínuo lexical que se forma entre as localidades indígenas e as cidades próximas a elas.

Os estudos que se fazem do PB falado por indígenas vão muito além de um registro linguístico, exploram comportamentos socioculturais desses grupos que influenciam as variações linguísticas. Fatores socioculturais, segundo Thomason e Kaufman (1988), são os principais fatores condicionadores da mudança linguística por meio do contato de línguas. Especificamente na situação de bilinguismo, os autores dizem que os diferentes processos de aprendizagem para as línguas, que é um fator sociolinguístico, podem implicar um bilinguismo desproporcional. Essa desproporcionalidade pode gerar desde interferências linguísticas até a perda de uma das línguas do falante ou da comunidade.

Lucchesi (2015) tem destacado o comportamento social de comunidades tradicionais afro-brasileiras isoladas e de áreas periféricas brasileiras, com base em Bortoni-Ricardo (2011), e salienta que nesses lugares os homens apresentam maior mobilidade de entrada e saída de suas localidades em relação às mulheres, assim, por possuírem maior interação com a variedade padrão urbana ou de prestígio, os homens são os indivíduos que implementam em suas comunidades novas formas linguísticas similares à variedade padrão.

Semelhante às observações de Lucchesi (2015), Alves (2018) também destacou uma maior mobilidade de homens em relação a mulheres de comunidades indígenas Araweté e Asuriní do Xingu. Alves revelou que há uma maior interação de indígenas homens com o contexto citadino e que implica a aquisição de um português mais diversificado e menos irregular (menos interferências) por eles, o que acarreta uma mudança gradual no PB de suas comunidades, isto é, o PB das comunidades indígenas 
passa a assemelhar-se com o PB de localidades urbanas de seu entorno influenciado socialmente pelo comportamento dos homens.

A variedade lexical do PB falado em comunidades indígenas Araweté e Asuriní do Xingu será analisada aqui a partir do mapeamento de dois itens lexicais, a saber: "banguela" e "cigarro de palha". Os itens compõem o Questionário Semântico-lexical (QSL) do projeto Atlas Linguístico do Brasil (ALiB) e pertencem a campos semânticos distintos: "corpo humano" e "convívio e comportamento social". O mapeamento apresenta as influências linguísticas da sociedade envolvente na variedade do PB de comunidades indígenas, mas também destaca como as línguas indígenas podem afetar essa variedade no nível lexical.

Os resultados do mapeamento apresentam uma diversidade lexical distinta entre os Asuriní do Xingu e os Araweté, influenciada pelos seus comportamentos sociais heterogêneos e pelos diferentes históricos de contato com a sociedade envolvente que cada uma das sociedades possui e que destacaremos aqui.

\section{Contexto da pesquisa}

Os Asuriní do Xingu e os Araweté são sociedades muito próximas geograficamente e linguísticamente. Eles vivem no município de Altamira no estado do Pará, região amazônica, e falam, além do $\mathrm{PB}$, línguas pertencentes à família linguística Tupí-Guaraní, de acordo com a classificação de Rodrigues e Cabral (2002).

A cidade de Altamira, além de ser um centro de referência aos indígenas, mantém sedes de instituições ligadas às suas causas, entre elas estão a sede da Fundação Nacional do Índio (FUNAI) e do Distrito sanitário especial indígena (DSEI). Além do mais, nessa cidade localiza-se a sede do empreendimento Norte Energia, empresa que foi responsável pela construção do Complexo Hidrelétrico de Belo Monte ${ }^{1}$ e que mantém reuniões constantes com as populações indígenas do Médio Xingu, região que comporta as áreas pertencentes aos Asuriní do Xingu (terra indígena (TI) Koatinemo) e aos Araweté (TI Araweté Igarapé Ipixuna).

\footnotetext{
${ }^{1}$ Macro projeto responsável pela construção da usina hidrelétrica de Belo Monte. A usina localiza-se na região do Médio Xingu, a $150 \mathrm{~km}$ da cidade de Altamira. O projeto também se fez presente na infraestrutura das comunidades indígenas, com a construção de escolas, postos de saúde, sistemas de abastecimento de água, casas, etc.
} 
Segundo Oliveira e Alves (2019), as situações linguísticas que as duas sociedades indígenas apresentam tomam o caminho em direção a um maior uso do português em relação à língua étnica, visto principalmente com os Asuriní do Xingu, os quais já apresentam um grau de bilinguismo muito avançado. $\mathrm{O}$ aumento do uso do português pelos indígenas dá-se devido a um novo contexto social que essas duas sociedades vivenciam e que foi motivada pela construção da usina hidrelétrica de Belo Monte.

Como já destacado, fatores sociais podem condicionar mudanças em uma ou várias línguas em contato. Entre esses fatores há a intensidade do contato linguístico, isto é, a intensa interação com uma variedade linguística distinta, o PB da cidade de Altamira. Os deslocamentos constantes dos indígenas para Altamira na última década influenciados pelo projeto Belo Monte conduziram a um intenso contato com o PB da cidade e que tem feito do português dos Asuriní e dos Araweté, adquirido de forma irregular com os primeiros contatos com a sociedade envolvente e marcado por muitas influências sociolinguísticas desses dois povos, assemelhar-se com a variedade do PB de Altamira, como observado também por Alves e Oliveira (2019).

Figura 1 - Áreas indígenas Asuriní (Koatinemo) e Araweté

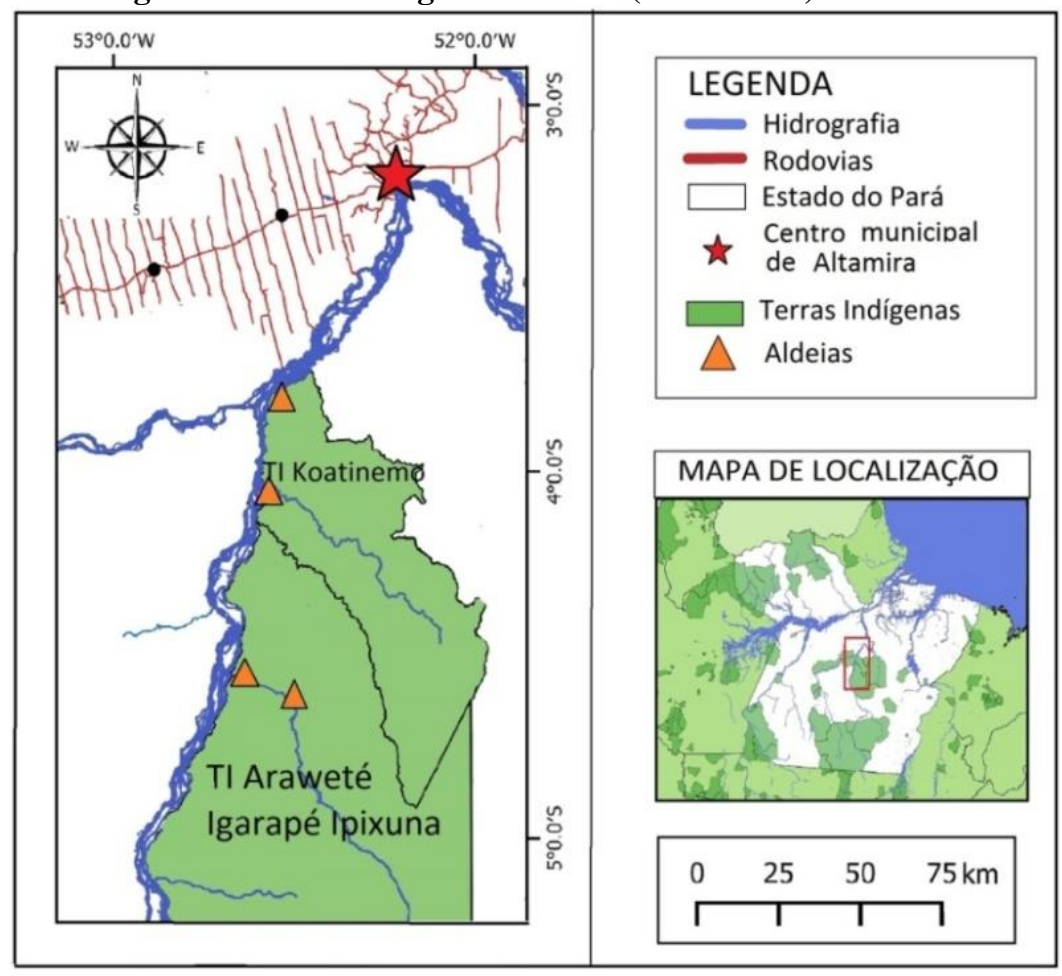

Fonte: Elaborado pelo autor 
A figura 1 destaca as quatro localidades (aldeias) investigadas na pesquisa em laranja e a distância delas para o centro municipal de Altamira. Nota-se que as comunidades Asuriní ficam mais próximas da cidade, logo sua interação com o contexto citadino é bem mais intensa. Os Asuriní quase não apresentam marcas, interferências linguísticas, em seu português, a não ser os indígenas mais velhos da comunidade.

\section{Procedimentos teórico-metodológicos}

Conforme a orientação da Dialetologia pluridimensional apresentada em Radtke e Thun (1996) e Thun (1998) que a pesquisa segue, apresentamos as dimensões extralinguísticas investigadas no presente estudo, a saber: dimensão diatópica (topostática), dimensão diassexual e dimensão diageracional. A adoção de outras dimensões, por exemplo, a diastrática ou a diatópica-cinética, ainda não é possível nesta pesquisa. As sociedades Asuriní do Xingu e Araweté ainda não dispõem de falantes suficientes para preencher o quadro estratificado de colaboradores adotando essas duas dimensões como já se vê em outros trabalhos de mesma natureza.

$\mathrm{Na}$ dimensão diatópica, quatro comunidades compõem a rede de pontos linguísticos, duas comunidades Asuriní (TI Koatinemo) e duas comunidades Araweté. A figura 2 apresenta os pontos pesquisados.

Figura 2 - Localização e identificação dos pontos linguísticos (aldeias)

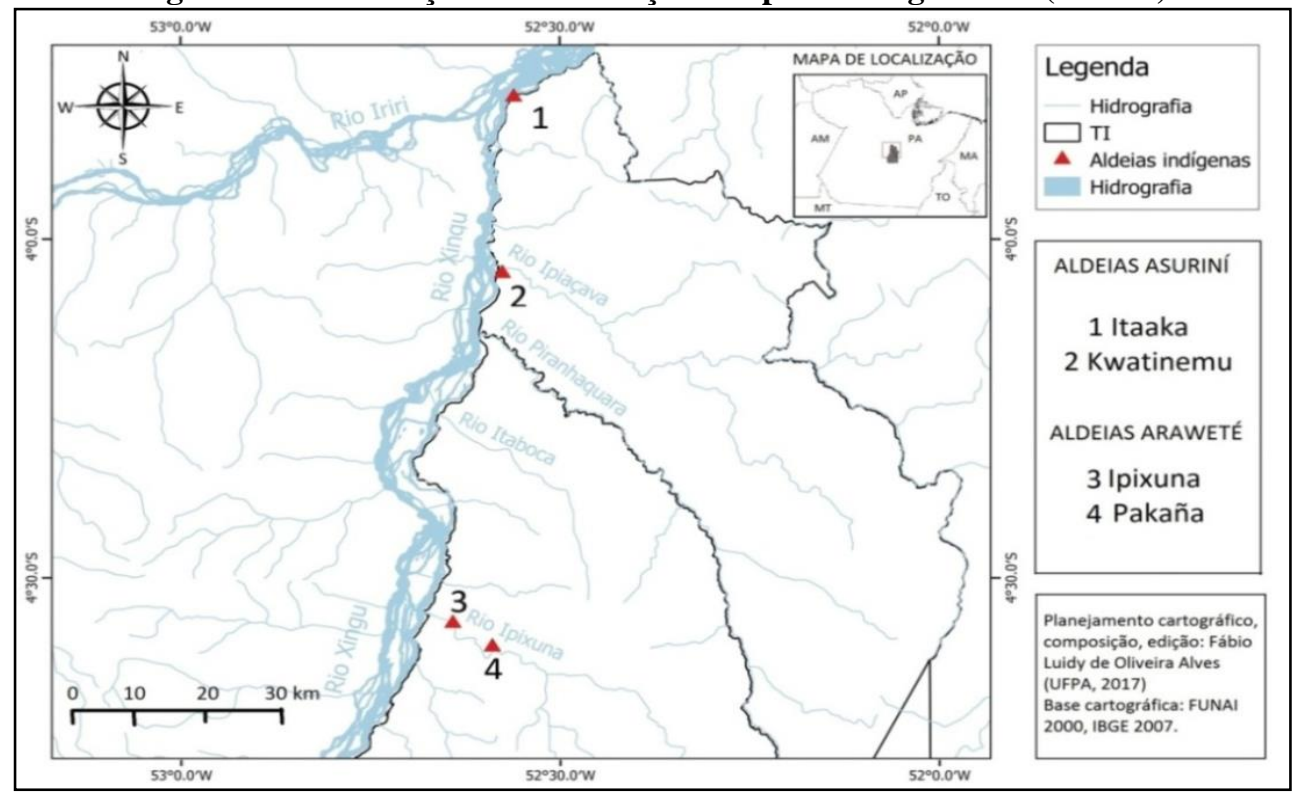

Fonte: Elaborado pelo autor 
Sobre os colaboradores, trabalhamos com quatro indígenas nativos por ponto. Eles totalizam 16 falantes. A definição da idade máxima dos colaboradores levou em conta a falta de indígenas falantes de português acima dos 45 anos, principalmente entre os Araweté. O quadro 1 apresenta o perfil dos colaboradores.

Quadro 1 - Perfil dos colaboradores

\begin{tabular}{|c|c|}
\hline Representação & Perfil estratificado \\
\hline H1 & Homem entre 18 e 25 anos ( $1^{a}$ geração) \\
\hline $\mathrm{H} 2$ & Homem entre 35 e 45 anos ( $2^{\mathrm{a}}$ geração) \\
\hline M1 & Mulher entre 18 e 25 anos ( $1^{a}$ geração) \\
\hline M2 & Mulher entre 35 e 45 anos ( $2^{\mathrm{a}}$ geração) \\
\hline
\end{tabular}

Para a formação do corpus, aplicamos aos colaboradores o $\mathrm{QSL}^{2}$ do projeto ALiB para a coleta de dados. Após a etapa de aplicação, os dados foram tratados, validados e cartografados.

Para a confecção das cartas linguísticas, fizemos uso do programa computacional QGIS 2.18 para construção, composição e edição das cartas e uso de mapas bases retirados dos bancos de dados cartográficos do IBGE e da FUNAI. A seguir, apresentamos uma carta linguística com finalidade explicativa para auxiliar a leitura das demais cartas em análise.

\footnotetext{
${ }^{2} \mathrm{O}$ QSL do projeto ALiB possui duzentas e duas questões distribuídas em quatorze campos semânticos. 
Figura 3 - Carta linguística com finalidade explicativa

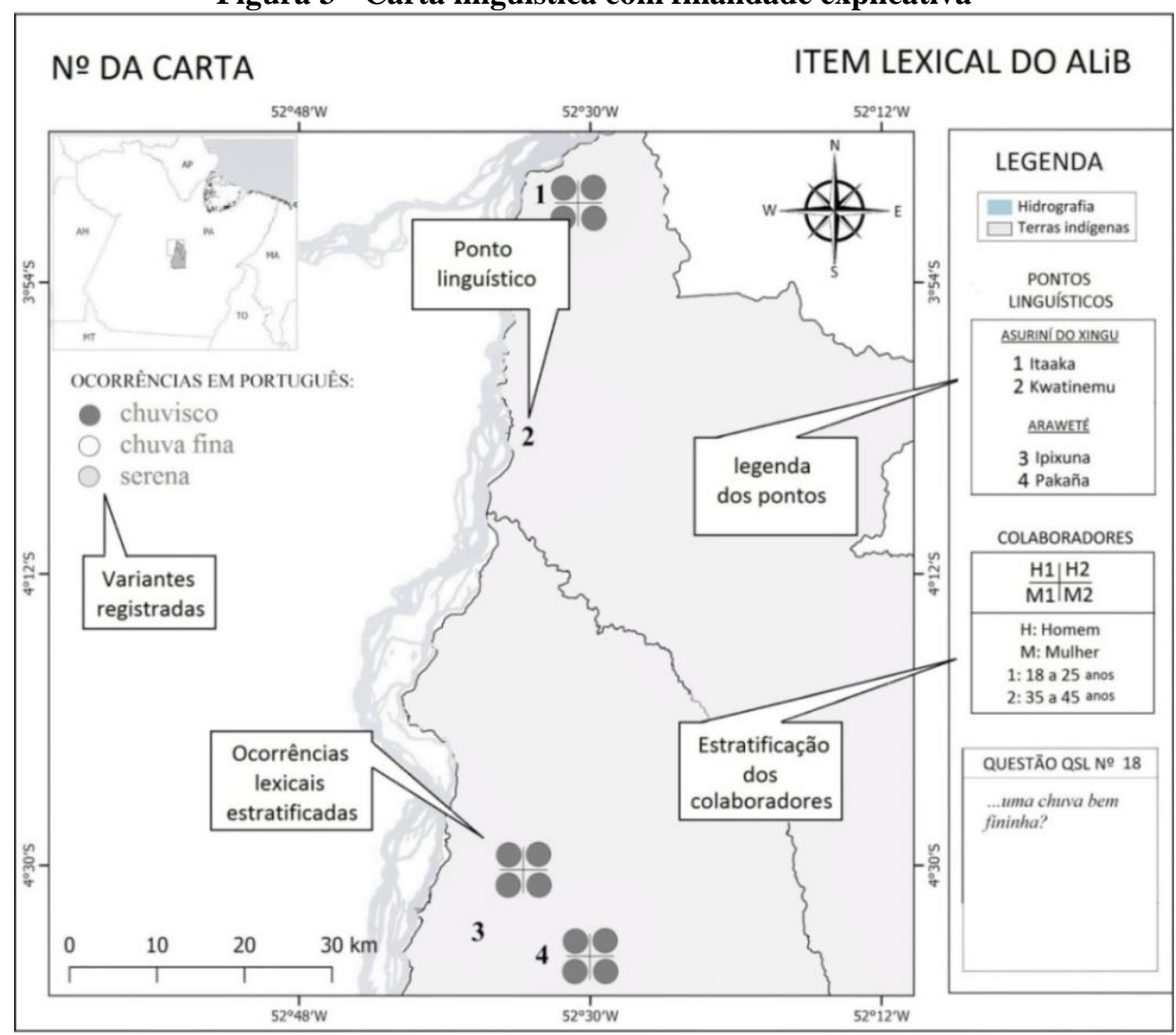

Fonte: Elaborado pelo autor

\section{Apresentação e discussão dos resultados}

Os resultados apresentados sobre o mapeamento dos itens lexicais "banguela" e "cigarro de palha" darão ênfase na análise diatópica e, quando necessário, apresentaremos discussões sobre as análises das dimensões diassexual e diageracional. As sociedades indígenas apresentam ampla produtividade lexical para específicos campos semânticos, assim, por trabalharmos com dois itens de campos semânticos distintos, determinado item apresentará caráter mais heteroléxico que o outro.

\subsection{Carta L20 (banguela)}

O item "banguela" foi uma das questões mapeadas para o campo semântico "corpo humano" que apresentaram produtividade de variantes. Esse campo apresentou quase metade de suas questões com resultados categóricos. Esses resultados são em decorrência de haver poucas variantes para as partes do corpo humano. A carta L20 
destaca o mapeamento para o item "banguela" com o registro de 18 ocorrências lexicais distribuídas entre 2 variantes, a saber: banguela e sem dente.

Figura 4: Carta L20 (Banguela)

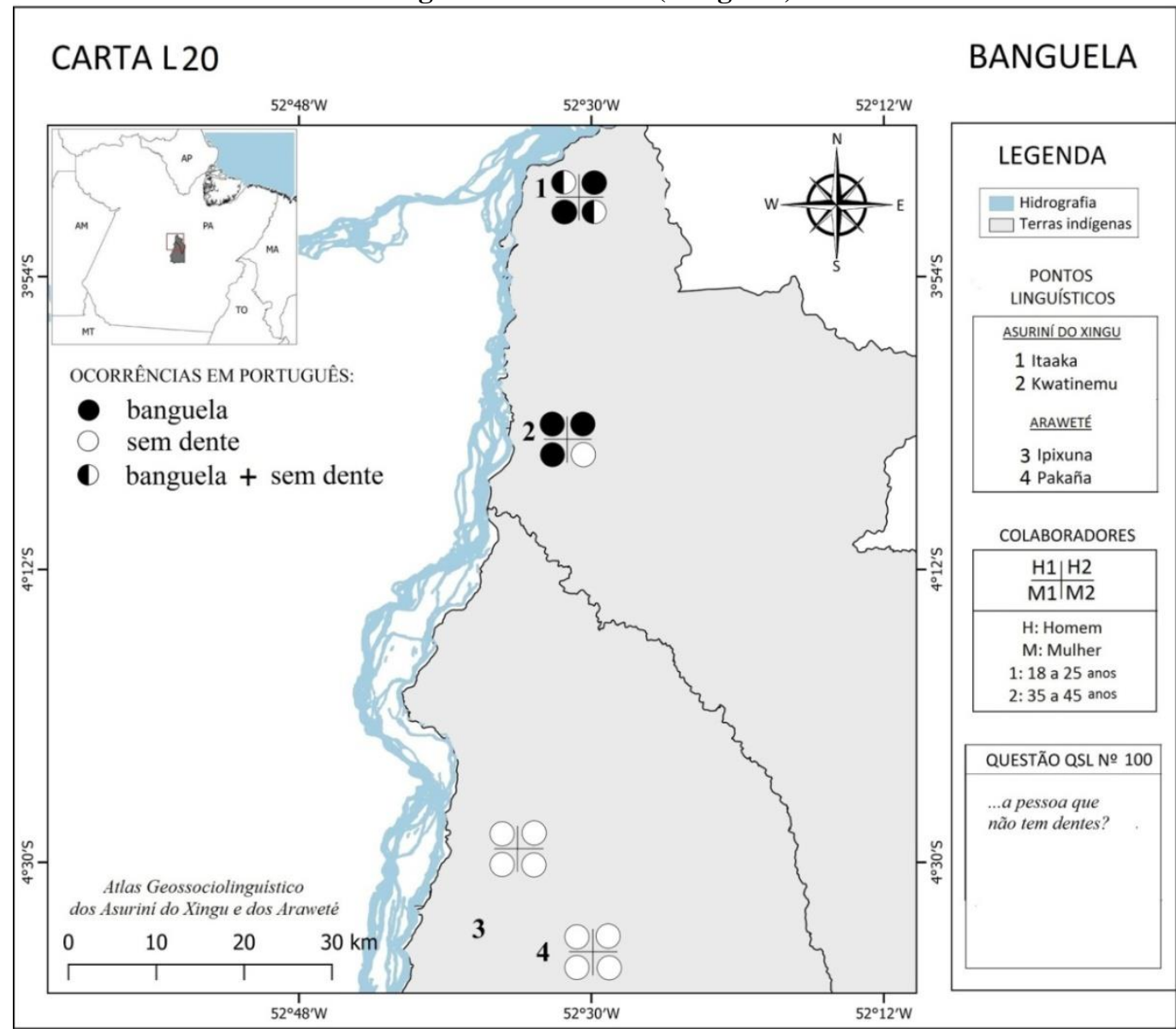

Fonte: Elaborado pelo autor

Observa-se na carta L20 que a variante sem dente foi preponderante com 11 ocorrências e banguela, menos frequente, apresentou 8 ocorrências. Cabe destacar que, nas comunidades Asuriní, a variante banguela foi predominante em relação a sem dente.

A sociedade Asuriní foi a única que apresentou diversidade lexical para o item "banguela". Essa diversidade deve-se ao intenso contato com a sociedade envolvente que os Asuriní apresentam, isto é, os vários anos de interação com a cidade de Altamira, em decorrência de sua proximidade geográfica. Assim, a variedade linguística de Altamira, a qual apresenta influências no PB das comunidade indígenas, como destacado por Alves (2018), acaba por influenciar muito mais as localidades bem próximas a ela, como as comunidades Asuriní. 
Alves (2018) destacou, com base em Guedes (2012), que no estado do Pará predomina a variante banguela e com menos frequência estão sem dente e desdentado, como podemos ver na figura 5 .

Figura 5: Carta 157 - Desdentado (ALIPA)

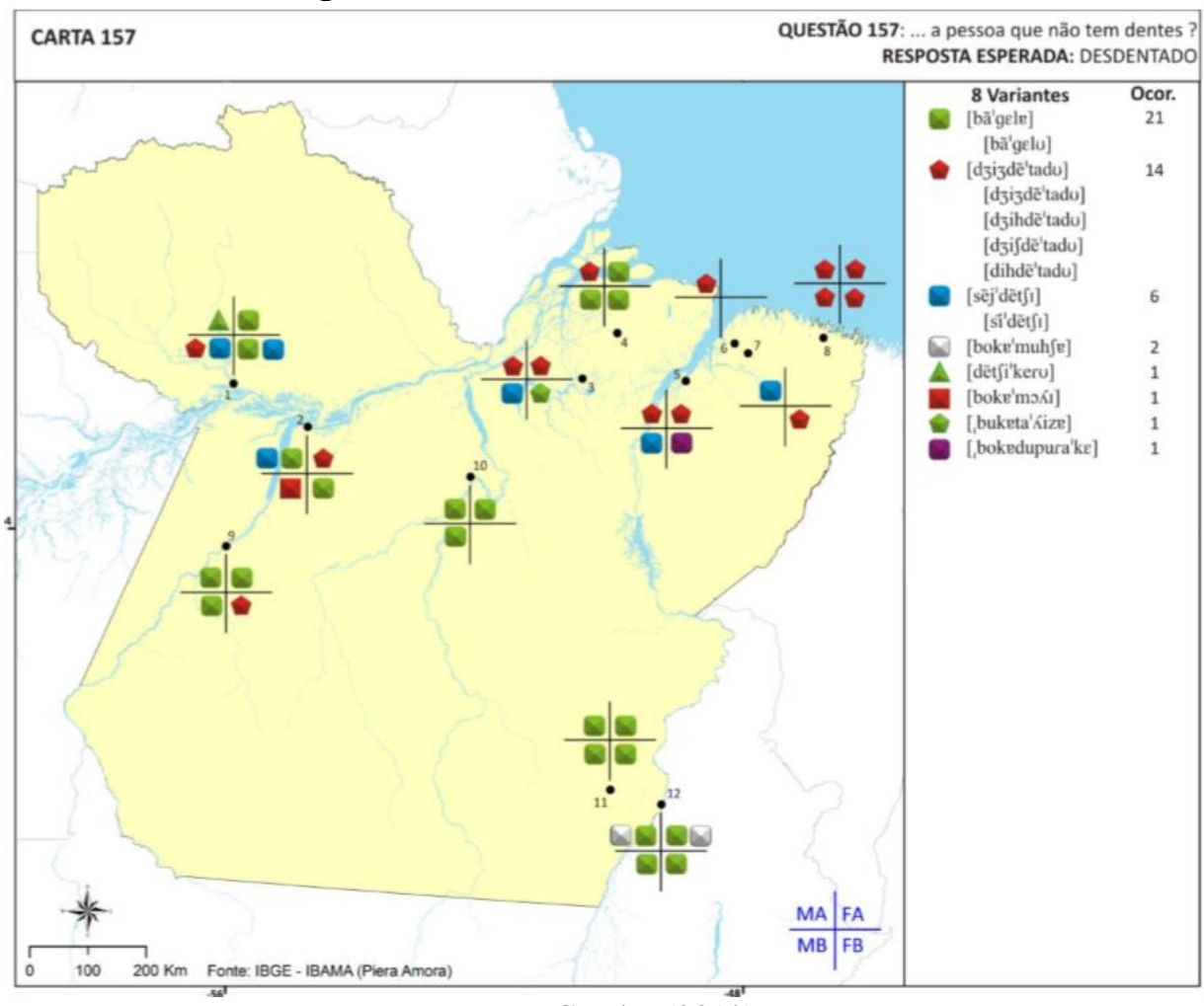

Fonte: Guedes (2012)

Na cidade de Altamira, ponto 10 no centro da carta 157, a variante banguela foi a única registrada. Essa informação reforça os indícios de influência linguística dessa cidade sobre as comunidades mais próximas, as comunidades Asuriní. A tabela 1 apresenta de forma detalhada as frequências das variantes pelos pontos pesquisados.

\begin{tabular}{|c|c|c|c|c|c|}
\hline \multirow{3}{*}{ Variantes } & \multicolumn{4}{|c|}{ Frequência das variantes por ponto } & \multirow{3}{*}{ Total } \\
\hline & \multicolumn{2}{|c|}{ Asuriní do Xingu } & \multicolumn{2}{|c|}{ Araweté } & \\
\hline & Itaaka & Kwatinemu & Ipixuna & Pakaña & \\
\hline Sem dente & $18,2 \%$ & $9,1 \%$ & $36,3 \%$ & $36,3 \%$ & $100 \%$ \\
\hline banguela & $57,1 \%$ & $42,9 \%$ & - & - & $100 \%$ \\
\hline
\end{tabular}


Pode-se notar que todas as comunidades apresentam a variante sem dente, variante diferente do padrão lexical da cidade de Altamira. Porém, a variante banguela, característica dessa cidade, só ocorreu nas comunidades Asuriní. Ela foi predominante no Itaaka, comunidade mais próxima geograficamente da cidade, o que confirma a influência lexical de Altamira nas comunidades do seu entorno.

Também fica claro no mapeamento que as comunidades indígenas apresentam preferências lexicais, os Asuriní tem preferências por banguela e os Araweté preferem sem dente. Isso revela que interação entre as comunidades Asuriní e Araweté não é muito intensa, mesmo estando tão próximas geograficamente e serem etnias falantes de línguas Tupí-Guaraní.

\subsection{Carta L27 (cigarro de palha)}

A carta L27 referente ao item "cigarro de palha" apresenta caráter heteroléxico. Ela destaca o registro de quatro variantes: fumo, tavarí, tabaco e cigarro, que obtivemos com a pergunta 145 do QSL "Que nomes dão ao cigarro que as pessoas faziam antigamente, enrolado à mão?’. A figura 6 destaca o mapeamento.

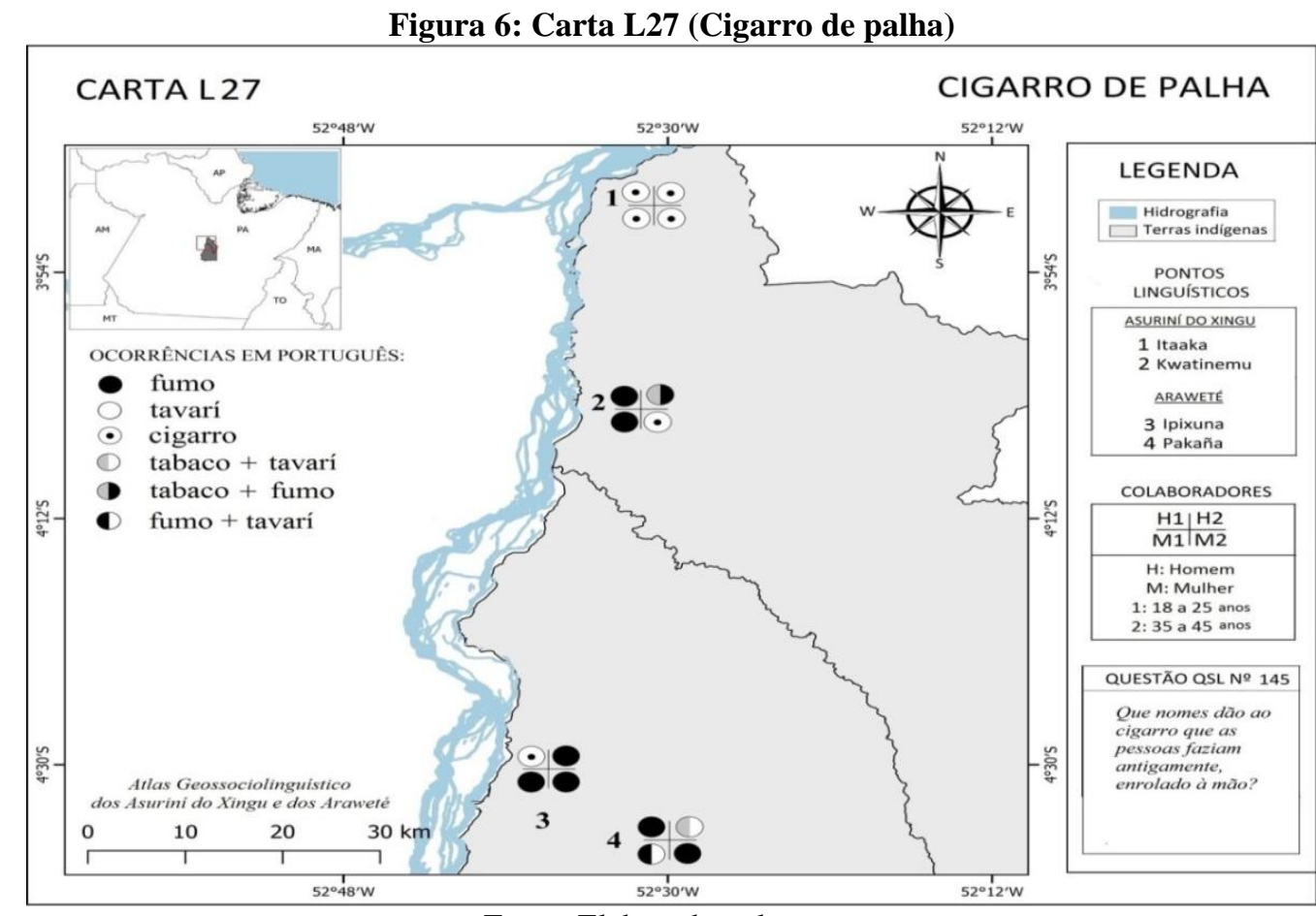

Fonte: Elaborado pelo autor 
Nota-se que fumo foi a variante com maior ocorrência na carta e apresentou $47,5 \%$ de frequência. A segunda variante mais frequente foi cigarro, com 31,5\%. Ambas as sociedades indígenas se mostraram muito produtivas à variação de "cigarro de palha". O destaque ficou para a variante fumo, preponderante nos Araweté, e para cigarro, presente em mais da metade das ocorrências dos Asuriní.

Além de preferências lexicais observadas em cada sociedade como já apresentado também na análise do item anterior e somando as outras distinções linguísticas entre os Asuriní do Xingu e os Araweté, destacadas por Alves (2018), podemos confirmar que a relação de interação entre essas duas sociedades não é intensa. A variedade lexical do português falado pelos Asuriní é diferente em alguns aspectos da variedade do português falado pelos Araweté.

Sobre a variante tavarí, ela é uma variante presente na língua Araweté e significa um tipo de fumo feito da árvore de tauarí. Mas, no português amazônico, chama-se também o cigarro enrolado à mão de "tauarí" (GUEDES, 2012), o que pode fazer com que alguns Araweté utilizem a sua variante linguística que é semelhante a palavra "tauarí" como estratégia para nomear o tal cigarro ao falar português. Ressaltamos que o projeto ALIPA registra a variante tauarí apenas em cidades à margem do rio Tapajós, a oeste do Pará, e que, em Altamira, predomina a variante porronca, seguindo o padrão do estado. É difícil dizer com exatidão se é um caso de interferência ou aprendizado irregular do PB dos Araweté, porque se necessita de mais informações sociolinguísticas.

A variante fumo pode ter aparecido nas comunidades indígenas a partir dos recentes acontecimentos em decorrência da realização do projeto Belo Monte em Altamira. Segundo Alves (2018), um dos acontecimentos foi as migrações de pessoas oriundas de outras cidades do estado Pará e que podem ter trazido a variante fumo para Altamira, porque ela é a segunda variante mais frequente do estado. A tabela 2 apresenta as frequências das variantes pelas comunidades indígenas. 
Tabela 2: Frequência diatópica para "cigarro de palha"

\begin{tabular}{|c|c|c|c|c|c|}
\cline { 2 - 5 } \multicolumn{1}{c|}{} & \multicolumn{4}{c|}{ Frequência das variantes por ponto } & \multicolumn{1}{c}{} \\
\hline \multirow{2}{*}{ Variantes } & Asuriní do Xingu & \multicolumn{2}{c|}{ Araweté } & \multirow{2}{*}{ Total } \\
\cline { 2 - 5 } & Itaaka & Kwatinemu & Ipixuna & Pakaña & \\
\hline fumo & - & $33,3 \%$ & $33,3 \%$ & $33,3 \%$ & $100 \%$ \\
\hline tavarí & - & - & - & $\mathbf{1 0 0 \%}$ & $100 \%$ \\
\hline tabaco & - & $50 \%$ & - & $50 \%$ & $100 \%$ \\
\hline cigarro & $\mathbf{6 6 , 6}$ & $16,7 \%$ & $16,7 \%$ & - & $100 \%$ \\
\hline
\end{tabular}

Constata-se que a variante fumo não predominou em nenhuma comunidade. Já tavarí foi característica do Pakaña e tabaco apresentou frequências iguais nas duas comunidades em que foi registrada. Por fim, cigarro foi mais produtiva no Itaaka.

Mesmo que as comunidades indígenas de uma mesma sociedade apresentem um padrão lexical semelhante, é possível ver que há algumas distinções lexicais entre essas comunidades. Na análise do item "cigarro de palha", observamos que Itaaka preferiu a variante cigarro e Kwatinemo optou por fumo.

Quanto à dimensão diageracional dos Asuriní, nota-se que os indígenas mais velhos foram os que apresentaram maior diversidade lexical no PB. A análise diageracional do item "cigarro de palha" destaca um dado incomum, porque, nas comunidades Asuriní, a faixa etária mais jovem é a que introduz novos usos lexicais na variedade de seu PB e é ela que apresenta um português com usos mais heteroléxicos, como podemos ver nos trabalhos de Alves e Oliveira (2018), Alves (2018), Oliveira e Alves (2019). Quanto à dimensão diassexual, observa-se mais diversidade lexical para os homens em relação às mulheres. Além disso, há a preferência da variante fumo pelos homens e de cigarro pelas mulheres. Essas preferências destacam a diferença sutil entre o PB de homens e mulheres Asuriní e podem complementar com o estudo de Alves (2018), o qual só observou a produtividade lexical na dimensão diassexual, isto é, o estudo só destacou que os homens Asuriní apresentavam um repertório lexical mais diversificado.

Quanto aos Araweté, não identificamos preferências lexicais em nenhum dos parâmetros adotados. Na dimensão diassexual, nota-se que os homens apresentaram mais diversidade lexical em relação às mulheres. Alves (2018) destacou que os homens Araweté apresentam um PB com caráter mais heteroléxico, porque são eles que 
interagem mais intensamente com a sociedade envolvente, local de falantes nativos de PB. Na dimensão diageracional, tanto os indígenas jovens quanto os mais velhos apresentaram a mesma produtividade de variantes. Destaca-se que o padrão para a sociedade Araweté é que os mais jovens apresentem usos mais heteroléxico para o PB de suas comunidades em relação aos mais velhos, os quais ainda apresentam desconhecimento de variantes do PB, como destacado por Alves (2018).

\section{Considerações finais}

Os resultados apresentados com o mapeamento dos itens lexicais "banguela" e "cigarro de palha" destacam influências sociolinguísticas na variedade lexical do PB dos Asuriní e dos Araweté. As discussões dos resultados mostram que os Asuriní do Xingu apresentam um PB mais diversificado que os Araweté e mais semelhante ao PB da cidade de Altamira, como destacado na análise do item "banguela". Isso se deve a relação intensa e de muitos anos que eles desenvolveram com essa cidade, o que forma uma espécie de continuun lexical entre a cidade de Altamira e as comunidades Asuriní.

Além de apresentar sobre as interações dos Asuriní e dos Araweté com a sociedade envolvente, destacamos que os homens são o perfil que mais insere novos usos lexicais na variedade do PB das comunidades indígenas, seja pela participação intensa no cotidiano da cidade, seja pela maior interação com os hábitos da sociedade envolvente.

\section{REFERÊNCIAS}

ALVES, F. L. de O. A variedade do português falado pelos Asuriní do Xingu e pelos Araweté: um estudo geossociolinguístico. 2018. Dissertação (Mestrado em Letras) Instituto de Letras e Comunicação, Universidade Federal do Pará, Belém, 2018.

ALVES, F. L. de O.; OLIVEIRA, M. B. Mapeamento do português falado em terras indígenas na Amazônia: efeito de fatores diatópicos e diastráticos. In: SÁ, E. J. de. (et al.). Diversidade linguística em comunidades tradicionais. Campinas, SP: Pontes Editores, 2018. 
ALVES, F. L. de O.; OLIVEIRA, M. B. A variação lexical dos itens chuva forte e cerração: um estudo geossociolinguístico em áreas indígenas. In: GUEDES, R. J. da C; COSTA, E. O. da (orgs.). Português Amazônico: etnicidade, identidade e diversidade. Belém: Edufra, 2019. (prelo)

BORTONI-RICARDO, S. M. Do campo para cidade: estudo sociolinguístico de migração e de redes sociais. São Paulo: Parábola, 2011.

GUEDES, R. J. da C. Estudo geossociolinguístico da variação lexical na zona rural do estado do Pará. 2012. Dissertação (Mestrado em letras) - Instituto de Letras e Comunicação, Universidade Federal do Pará, Belém, 2012.

Perfil geossociolinguístico do português em contato com línguas tupi-guarani nos estados do Pará e Maranhão. 2017. Tese (Doutorado em Letras) - Instituto de Letras e Comunicação, Universidade Federal do Pará, Belém, 2017.

COSTA, E. O. da. Estudo Geossociolinguístico do Léxico do Português Falado em Áreas Indígenas de Língua Tupí-Guaraní nos Estados do Pará e Maranhão. 2018. Tese (Doutorado em Letras) - Instituto de Letras e Comunicação, Universidade Federal do Pará, Belém, 2018.

LUCHESI, Dante. Língua e sociedade partidas: a polarização sociolinguística do Brasil. São Paulo: Contexto, 2015.

OLIVEIRA, M. B.; ALVES, F. L. de O. Línguas em contato na Amazônia: contornos diatópicos e diastráticos. In: MOUTINHO, L. C.; COIMBRA, R. L.; FERNÁNDEZ REI, E.; SOUSA, X.; GÓMEZ BAUTISTA, A. (eds.). Estudos em variação linguística nas línguas românicas. Aveiro: UA Editora, 2019.

RADTKE, Edgar; THUN, Harald. Nuevos caminhos de la geolinguística românica. Un balance. In: RADTKE, Edgar; THUN, Harald. Neue Wege der Romanischen Geolinguistik. Kiel: Westensee-Verlag, 1996.

RODRIGUES, A. D.; CABRAL, A. S. A. C. Revendo a classificação interna da família Tupi-Guarani. In: Atas do I Encontro Internacional do GTLI da ANPOLL, vol. 1, Belém: EDUFPA, 2002.

THOMASON, S. G.; KAUFMAN, T. Language contact, creolization, and genetic linguistics. Berkeley: University of California Press, 1988.

THUN, Harald. La geolinguística como linguística variacional general (con ejemplos del Atlas linguístico Diatópico y Diastrático do Uruguay). In: INTERNATIONAL 
CONGRESS OF ROMANCE LINGUISTICS AND PHILOLOGY. Atti del XXI Congresso internazionale di linguistica e filologia romanza, 21., 1995, Palermo. Tübingen: Niemeyer, 1998, p. 701-729. 